\title{
How Robust is Comparative Advantage?
}

\author{
Alan V. Deardorff*
}

\begin{abstract}
This paper reviews the theoretical development of the concept of comparative advantage, starting with the two-good model of Ricardo and the two-good extension and reinterpretation by Haberler. In both, the presence of comparative advantage provides the scope for countries to gain from trade by specializing, and the pattern of that trade is explained by the pattern of comparative advantage. These strong results of the twogood model can be extended under certain circumstances to multiple goods and countries, but under more general assumptions such strong results no longer are assured. Instead one can derive much weaker results, usually in the form of correlations between comparative advantage and trade, and these weaker results hold in a much wider variety of circumstances. The paper examines those assumptions that permit such generalizations, but then also examines when those assumptions are most likely to fail, and what happens as a result.
\end{abstract}

\section{Introduction}

Comparative advantage is certainly one of the most basic ideas in economics, underlying much of our understanding both of why countries trade the way that they do and why they benefit from doing so. But it is also a difficult concept for many people to understand, and seemingly even more difficult for them to believe once they do understand it (and especially if they don't). It is common to hear critics of trade say that comparative advantage may have been valid two centuries ago when David Ricardo first proposed it, but that for various reasons it is wrong or irrelevant in the world of today. Therefore it is perhaps worthwhile to restate just what comparative advantage means, and what it does and does not imply. In this paper I will review what I think we know, from the standpoint of economic theory, about the meaning and the generality of comparative advantage.

I will start, in section 2, by recalling the simplest models in which comparative advantage plays its strongest role: the Ricardian model in terms of labor costs and Haberler's model in terms of opportunity cost, both in the two-good context in which simple diagrams provide compelling illustrations. I will then explore some simple generalizations of these results, especially to more goods and countries, in section 3. But I will also note the limitation of these generalizations for making strong statements about the pattern of trade. In section 4 I recall my own result from 25 years ago, showing that a particular definition of comparative advantage suffices under quite general assumptions to provide a very weak explanation of patterns of trade in the sense of a correlation, and I examine the assumptions under which this result both does, and does not, hold. I conclude in section 5 with-what else?-my conclusion from all of this.

\footnotetext{
* Deardorff: Department of Economics, University of Michigan, Ann Arbor, MI 48109-1220, USA. Tel: 734-764-6817; Fax: 734-763-9181; E-mail: alandear@umich.edu. I have benefited from the comments of participants at the January AEA session, including especially Daniel Bernhofen, Bill Ethier, and Ron Jones. Jonathan Eaton also alerted me to an error in my thinking that I have since corrected.
} 


\section{Comparative Advantage with Two Goods: Ricardo, Haberler}

Ricardo presented comparative advantage with a numerical example of two goods and two countries. Production required labor only, and in fixed amounts per unit of output. Comparative advantage was therefore defined naturally in terms of the unit labor requirements (or equivalently, labor productivities) in the two industries and two countries. Letting $a_{g}^{c}$ be the amount of labor needed to produce one unit of good $g$ in country $c$, then country 1 has a comparative advantage in producing good 1, compared to country 2 and good 2 , if it can produce it with less labor relative to good 2, compared to country 2:

$$
\frac{a_{1}^{1}}{a_{2}^{1}}<\frac{a_{1}^{2}}{a_{2}^{2}} .
$$

The importance of this can be shown in several ways. One is to look at the possible world outputs of the two goods by the countries together, assuming that each has a fixed endowment of labor. It can then be shown that world output is increased if one or both specialize in producing only the good in which it has a comparative advantage. Equivalently, one can show that an appropriate marginal reallocation of labor in both countries, in the direction of their respective comparative advantages, will increase world output of one or both goods. Both of these results can also be illustrated in terms of production possibility frontiers (PPFs) as in Figure 1, where the left and middle panels show PPFs for countries 1 and 2 respectively. The right panel shows their sumthat is, the set of all possible world outputs obtained by adding feasible output vectors from countries 1 and 2. Condition (1) implies that the PPF of country 1 is flatter than that of country 2, as drawn. And this in turn implies, as seen in the figure, that the world PPF can be reached only by one or both countries specializing completely in the good in which it has a comparative advantage.

Arguments such as these show that, for the world to enjoy more of goods 1 and 2 than are available in autarky, specialization in accord with comparative advantage is necessary. That does not, in and of itself however, imply either of the properties that we normally associate with comparative advantage: that countries individually gain from comparative-advantage-determined trade, and that free trade will in fact lead to countries specializing in this way. For these implications, we need not just the presence of comparative advantage, but also an economic structure that induces the countries to take maximal advantage of their production and trade possibilities. Such a structure is provided by perfect competition, with profit-maximizing producers and utilitymaximizing consumers interacting atomistically to achieve maximum value and

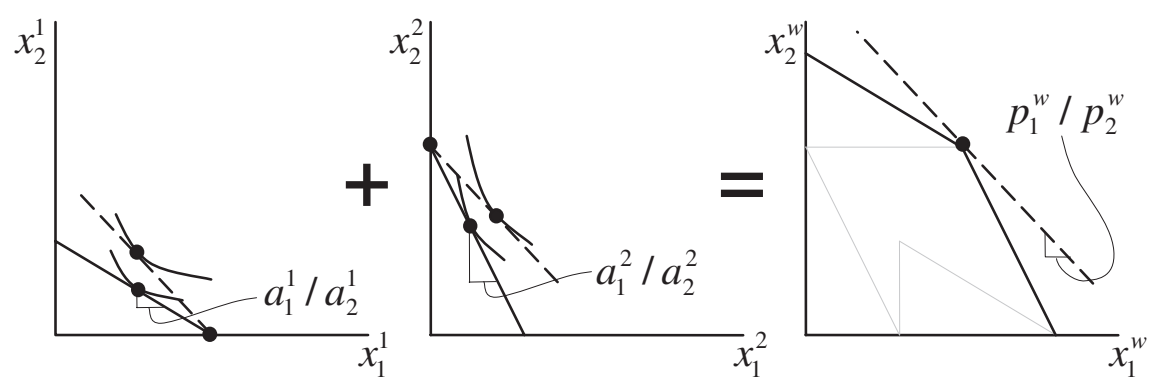

Figure 1. The Ricardian Model: Production Possibilities and a Free-Trade Equilibrium 
utility at given prices, which are in turn determined so as to clear markets. In that case, and assuming also free and frictionless trade, world prices will be determined to support production on the world PPF with one or both countries therefore specializing in its comparative-advantage good and therefore necessarily exporting it to the other country. Such a free-trade equilibrium is shown by the dashed lines in Figure 1.

A strict gain from trade in this case is not assured, since one country may find that equilibrium world prices are exactly equal to its autarky prices, and therefore that it neither gains nor loses from trade. And indeed we cannot really ascribe the avoidance of loss from trade to the presence of comparative advantage, since the competitive structure assures it. On the other hand, it is true that if a Ricardian economy does gain from trade, consuming therefore outside its PPF, then in a perfectly competitive market economy it can only do so if it does in fact export the good in which it has a comparative advantage.

Thus the gains from trade and the pattern of trade are related, but not in the sense that trade according to comparative advantage is necessarily strictly beneficial. Rather it is the gain from trade that implies the pattern of trade, not the reverse. A country that gains from trade at some particular world prices must, in this model, specialize in the good whose world relative price is higher than its autarky relative cost, while a country that neither gains nor loses from trade must face world prices equal to its costs. Thus if one or both countries gain from trade, while neither lose, world prices must lie at or between their relative costs, implying that each country exports the good in which it has comparative advantage.

The Ricardian model is special in many ways, but the most obvious difference from more standard modern trade models is the assumption of constant costs. Both the Heckscher-Ohlin model and the specific factors model have marginal costs that increase as more of a good is produced, leading to production possibilities that are concave to the origin, as in the left and middle panels of Figure 2. In such a framework, which was considered by Haberler (1930), comparative costs are not uniquely defined, since they depend on the particular points on two countries' respective PPFs that are selected for comparison. Nonetheless the behavior of countries in such a model is not that much different from the Ricardian model, except for the fact that countries can now continue to produce both goods even at prices that differ from autarky.

Haberler's contribution here was to recognize that what was important for trade, the gains from trade, and comparative advantage, even in the Ricardian model, was not labor costs per se, but rather the opportunity cost, at the margin, of producing one good instead of another. If this varies with levels of output, as in Figure 2, then marginal opportunity costs may become equalized as a result of trade (if it is free), and

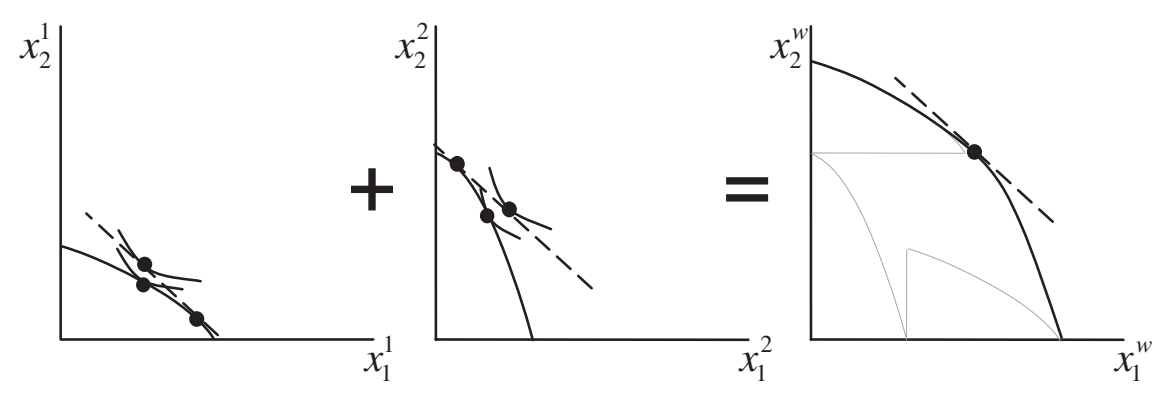

Figure 2. Haberler Model: Production Possibilities and a Free-Trade Equilibrium 
thus become unhelpful as a guide to trade. But marginal opportunity costs in autarky, given by the slope of the PPF at the autarky equilibrium, are in any case the more relevant indicator, both of the potential for gain from trade and of the direction of specialization needed to achieve it. For if opportunity costs differ between two countries in autarky, then a small reallocation of resources increasing the output in each country of the good for which its opportunity cost is smaller than abroad, will again permit a rise in world output. Under the Ricardian assumption of constant labor requirements, low opportunity cost is equivalent to low relative unit labor requirements, and it therefore provides an equivalent definition of comparative advantage. In more general models, a comparison of marginal opportunity cost at the autarky equilibria is the more valid and useful definition of comparative advantage.

As in the Ricardian model, the existence of comparative advantage by the opportunity-cost definition has its most direct implication for the gains from trade. If opportunity costs differ in autarky, then with perfect competition free trade will lead to gains from trade for one or both countries. Indeed strict gains for both countries now occur so long as both PPFs are strictly concave-i.e. if marginal opportunity cost is strictly increasing as output rises. On the other hand, if opportunity costs do not differ in autarky, so that neither country has a comparative advantage in either good, then there is no scope for gain from trade in this model.

The implication for the pattern of trade then follows from the gains from trade. If, for example, a country were to export the good in which it does not have a comparative advantage, perhaps by subsidizing its production or its export, then it would necessarily lose from trade. This is illustrated in Figure 3, where a country faces a world relative price of good 1 that is higher than its autarky price, so that it has a comparative advantage in good 1. But here I suppose that it nonetheless produces less of good 1 , and more of good 2, than in autarky, resulting in exporting good 2. As can be seen, its loses from this trade. Thus, in order to gain from trade such a country must export the good in which it has comparative advantage. ${ }^{1}$

It should be noted too that while trade in accord with comparative advantage is necessary for the gains from trade, it is not sufficient, even in this simple model. Figure 4 shows a case of a country with comparative advantage in good 1 that expands production too far in the direction of good 1-perhaps due to a subsidy to its production

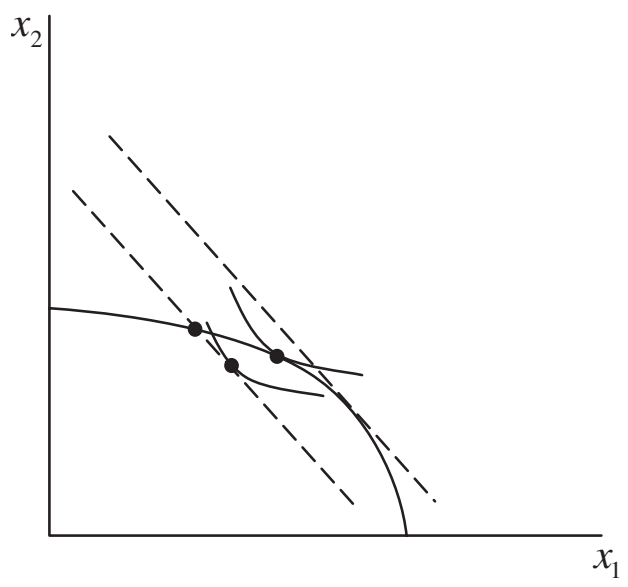

Figure 3. Trade Contrary to Comparative Advantage Reduces Welfare 


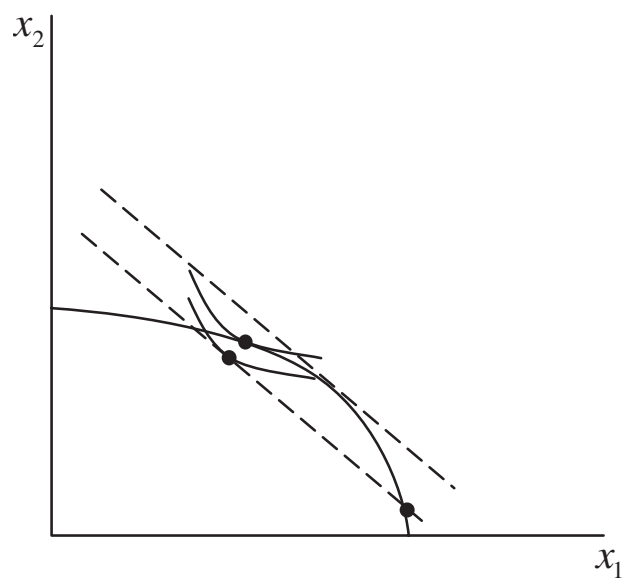

Figure 4. Too Much Trade in Accord with Comparative Advantage Reduces Welfare

or export—and as a result makes itself worse off by trade, even though that trade is in the direction dictated by comparative advantage.

The conclusion, then, from both the Ricardian and the Haberler two-good models, is that comparative advantage can be usefully defined in terms of a comparison of relative autarky prices, which also represent marginal opportunity costs in autarky. A difference in relative autarky prices, and thus the presence of comparative advantage, implies the potential to increase world output by reallocating resources within the two countries. Combined with market structures of perfect competition, comparative advantage also implies that unless policies interfere with market incentives, countries stand to gain from trade in the sense that at least one country will gain and neither will lose. And this gain from trade is achievable only if countries each export the good in which they have comparative advantage.

\section{Strong Generalizations}

The Ricardian model generalizes easily to more than two of either goods or countries, though not quite so easily to more than two of both together. The strong generalization is in terms of a "chain of comparative advantage." This was shown first, it seems, by Haberler (1930) himself, for the Ricardian model. That is, suppose that there are two countries, as before, but multiple goods $g=1, \ldots, G$. Number the goods in order of country 1's relative labor requirements:

$$
\frac{a_{1}^{1}}{a_{1}^{2}}<\frac{a_{2}^{1}}{a_{2}^{2}}<\cdots<\frac{a_{G}^{1}}{a_{G}^{2}} .
$$

Then it can be shown that all of country 1's exports will lie to the left in this chain of all of country 2's exports. With free trade there will exist a single "break" in this chain, either between two goods or exactly at one of them, such that country 1 will export all goods to the left of this break and import all goods to its right. Indeed, this result is easily extended to an infinite number of goods, as done by Dornbusch et al. (1977).

Similarly, if there are only two goods but multiple countries, $c=1, \ldots, C$, then a similar ranking can be constructed over the countries' relative labor requirements for producing the two goods: 


$$
\frac{a_{1}^{1}}{a_{2}^{1}}<\frac{a_{1}^{2}}{a_{2}^{2}}<\cdots<\frac{a_{1}^{C}}{a_{2}^{C}} .
$$

Now all exporters of good 1 will lie to the left of all exporters of good 2, and with free trade a single break in this chain will separate all exporters of good 1 on the left from all importers of good 1 on the right.

These are nice results, but their generality is of course limited by the fact that the world inconveniently seems to contain more than two of both goods and countries. This can be gotten around, perhaps, by aggregating either goods or countries, although the assumptions needed to do that cleanly are unlikely to be believable. The twocountry chain in (2) at least has the advantage that one of the countries can be taken to represent the rest of the world, especially if the country concerned is small. In that case, labor requirements in the large country 2 can be replaced by world prices:

$$
\frac{a_{1}^{1}}{p_{1}^{w}}<\frac{a_{2}^{1}}{p_{2}^{w}}<\cdots<\frac{a_{G}^{1}}{p_{G}^{w}} .
$$

This permits a single country's trade in all goods to be determined by this ranking of its labor costs relative to world prices.

Also, both of these chain results can be used to make partial statements about patterns of trade in just two goods or two countries, even when there exist more than two of both. For example, using (2), if countries 1 and 2 are any two of a larger number of countries in the world, we can still say that with free trade all of the goods that country 1 exports (to country 2 or otherwise), and that country 2 does not export, will lie to the left in this chain of all of the goods that country 2 does export. Of course, any number of the goods may not be exported by either country, and these may lie anywhere in the chain. So this result does not as fully specify the pattern of trade as in the two-country case. But it still shows some role for comparative advantage.

Similarly, (3) can be used with more than two goods to clarify which of many countries may export a particular pair of goods, 1 and 2 . That is, all of the countries that export good 1 and not good 2 must lie to the left in this chain of all of the countries that export good 2. Again this tells us nothing about the positions of countries that export neither good.

A more complete specification of the patterns of specialization and trade in the Ricardian model with many goods and countries was provided by Jones (1961). He showed that an efficient assignment of countries to goods in a many-good, many-country Ricardian model is to minimize the product of countries' unit labor requirements. This is a bit less complete than it sounds, however, because the question of how many countries produce each good must be solved separately. Nonetheless it shows compellingly that specialization is associated somehow with low unit labor requirements. Also "low" here must be interpreted in comparison to other countries and other goods, much as in (1), since the model requires that each country produce something, and thus contribute at least one of its unit labor requirements to one of these products.

Allowing for increasing costs, as in Haberler's model, the chain result in (3) - for two goods and multiple countries-is easily extended. Simply replace the $a$ 's with autarky prices, $\tilde{p}_{g}^{c}$, for good $g$ in country $c$ :

$$
\frac{\tilde{p}_{1}^{1}}{\tilde{p}_{2}^{1}}<\frac{\tilde{p}_{1}^{2}}{\tilde{p}_{2}^{2}}<\cdots<\frac{\tilde{p}_{1}^{C}}{\tilde{p}_{2}^{C}} .
$$


The result then holds exactly as in the Ricardian case: all of the countries that export good 1 will lie to the left of all countries that import it. This follows easily from the fact that each country has an excess supply of, say, $x_{1}$ for any world relative price of $x_{1}$ that is above its autarky price, and an excess demand below.

The result for multiple goods is harder to get, since in general the relative supplies of two goods may depend on the price of a third. However, in the special case of the Heckscher-Ohlin model with multiple goods but just two factors of production, the multi-good chain result generalizes easily for countries whose factor endowments place them in different cones of specialization. Such countries will specialize in different goods, and under free trade those goods will be distinct in terms of the intensity with which they use the factors. That is, goods can be ranked in terms of, say, their relative capital intensity compared to labor, in much the same way that they are ranked in (2). Indeed, that ranking also corresponds to their relative autarky prices, and thus to their marginal opportunity costs, exactly as in Haberler's model with increasing costs. And that ranking suffices to determine trade in the same manner as the chain proposition: all of the exports of a country in a more capital-abundant cone of specialization will be more capital-intensive than all of the exports of a country in a less capital-abundant cone. Indeed, this is also true in this model under free trade with large numbers of both goods and factors. All of this was shown, for example, in Deardorff (1979).

That paper also shows, however, that this strong relationship may break down if we move away from free trade. Without free trade countries face different prices, and with multiple goods, prices of one good can alter the viability of producing another good in ways that interfere with comparative advantage. The simplest such case-shown in Deardorff (1979) for the Heckscher-Ohlin model and in Deardorff (2005) for the Ricardian model-is when some goods serve as intermediate inputs to the production of other goods. Then a trade barrier on an input that raises its price can make production of the corresponding final good too costly to survive, even though the country might otherwise possess a relatively low cost of producing the final good. Also, and even without intermediate inputs, the combination of both multiple countries and multiple goods can, in the presence of trade barriers, alter factor prices sufficiently to change the entire set of goods in which a country can compete with its many trading partners. Thus, although comparative advantage provides rather strong predictions of trade patterns in simple cases, it fails to do so in models that allow for even a small amount of realistic complication, such as trade barriers, intermediate inputs, and large numbers of both countries and goods.

This is only true, however, of the ability of comparative advantage to predict trade patterns. It should not be forgotten that another implication of comparative advantage-and arguably the more important one-is that it predicts and explains gains from trade. This implication is not in the least undermined by the difficulties just mentioned of using comparative advantage to predict trade patterns.

Admittedly this is partly because an important part of the gains-from-trade result has nothing to do with comparative advantage, but arises simply from perfect competition. One of the theorems of welfare economics tells us that, if an economy has perfect competition and a convex technology, then a market equilibrium will be Paretooptimal. A corollary of that result is the basic gains-from-trade result of Samuelson (1939) that free trade cannot make a country worse off compared to autarky, and will make it better off as long as it faces prices, with trade, that differ from those in autarky. All that comparative advantage does is to provide a reason for prices with trade to differ from autarky, and thus to assure that the gains from trade are positive rather than zero. 
But even though this contribution may be small, it is nonetheless important. While as trade economists we may be very interested in explaining the pattern of trade, the important message of comparative advantage theory for the world is that trade is beneficial. And it is this message that the public most often distrusts. We must be careful not to let any failures of theory to predict trade patterns suggest that we also have doubts about the welfare implications of comparative advantage. There may be good reasons to doubt that trade in the real world is beneficial, but these reasons should rest on departures from the assumptions of the basic welfare theorem-market failures, non-convex technologies, etc.- - not on the sorts of things that may cause comparative advantage to mis-predict the pattern of trade.

\section{Weak Generalizations}

The failure of chain propositions to survive the introduction of trade barriers and intermediate inputs does not mean that comparative advantage can say nothing at all about the pattern of trade. What is needed, however, is to weaken what we attempt to say. Instead of trying to make statements that apply to every good, for example ("every export lies to the left of every import"), we might look for only average relationships ("exports lie on average to the left of imports"). This, in effect, is what has been found to be theoretically true as indicated by correlations.

Such results were first derived independently by Dixit and Norman (1980) and Deardorff (1980). Using autarky prices as indicators of comparative advantage, and letting $T_{g}^{c}$ be the net exports of good $g$ by country $c$, both showed that

$$
\tilde{p}^{c} T^{c}=\sum_{g} \tilde{p}_{g}^{c} T_{g}^{c}<0
$$

On its face, since the vector $T^{c}$ is a mixture of both positive and negative elements (exports and imports), and since autarky prices are all positive, this result suggests that exports have on average lower autarky prices than imports.

For a simple example, consider a small open economy that faces given world prices $p_{g}^{w}$ and whose trade is balanced at those prices. Then separating the vector $T_{g}^{c}$ into its positive and negative components, $X_{g}^{c}=\max \left\{T_{g}^{c}, 0\right\}$ and $M_{g}^{c}=\max \left\{-T_{g}^{c}, 0\right\}$, (6) implies:

$$
\sum_{g} \frac{\tilde{p}_{g}^{c}}{p_{g}^{w}} \frac{p_{g}^{w} T_{g}^{c}}{\bar{X}^{c}}<\sum_{g} \frac{\tilde{p}_{g}^{c}}{p_{g}^{w}} \frac{p_{g}^{w} M_{g}^{c}}{\bar{M}^{c}},
$$

where $\bar{X}^{c}=\bar{M}^{c}=\Sigma_{g} p_{g}^{w} X_{g}^{c}$. That is, the trade-weighted average of the country's autarky prices of goods it exports, relative to world prices, is less than the trade-weighted average of the relative prices of its imports.

An equivalent but more flexible way to formalizing such averages is to examine correlations. In Deardorff (1980) I derive four of them, the broadest being a negative correlation across all goods and countries between autarky prices and quantities of net exports. $^{2}$

These results are certainly weak, since they do not tell us whether any particular good will be exported or imported by any particular country. That is appropriate, however, since the assumptions needed to derive these results are general enough to include those features - intermediate inputs and trade barriers, in particular-that could potentially cause any particular good to be traded in either direction. I will discuss those assumptions in a moment. 
But before I do, let me note that, in an important sense, these correlation results are just as strong as what the Ricardian and Haberler models are able to say in the twogood, two-country case. In those simple models, there are really only two ways that (balanced) trade can proceed: country 1 exports good 1 and imports good 2; or it exports good 2 and imports good 1. Comparative advantage cuts the set of possible outcomes in half: given inequality (1), only the first of these possibilities can arise. The correlation result also cuts the set of possible trade patterns-which is of course much larger when there are many goods and countries-in half: only those trade patterns that give rise to the specified negative correlation can arise.

Under what assumptions do these results obtain? This is important, because the whole point of the exercise is that it is more general than the other formulations discussed earlier. Although these assumptions are stated in Deardorff (1980), and also in a sequel that relaxed some of them in Deardorff (1994), it may be worthwhile to give them more explicit attention. The following are the assumptions that are accommodated in these two papers, and thus that are consistent with the theoretical validity of at least some version of the comparative-advantage correlation result:

\section{Assumptions Consistent with Comparative-Advantage Correlation}

- Multiple goods and countries: this is of course the assumption that I have stressed here, since it presents the most immediate difficulty for extending the graphical kinds of analysis in Figures 1 and 2. It is also the assumption that was most glaringly needed when others attempted to take the trade theory of two-dimensions to the data.

- Tariffs and other artificial trade costs: in two-good models, tariffs only reduce the volume of trade but cannot change its direction. With many goods this is not the case, for particular goods as already noted. But it turns out that artificial barriers to trade cannot overturn the correlation result unless they act, on net, to encourage trade rather than limit it. Thus sufficiently large export subsidies could overturn comparative advantage, as we saw in Figure 3, but as long as trade policies restrict trade rather than promoting it, both the gains from trade and the average relationship between comparative advantage and trade will continue to hold. This is perhaps important, if only because of the common public perception that if other countries are restricting trade, then the theory of comparative advantage is somehow undermined and that therefore our country should restrict trade as well. ${ }^{3}$

- Transport costs and other real trade costs: transport costs have effects similar to tariffs, and they serve to discourage trade, not to promote it, so it is not surprising that they too leave the weak version of the law of comparative advantage unscathed. Their analysis is somewhat trickier than tariffs, however, because of their use of real resources. ${ }^{4}$ Only recently have transport costs been given much attention in the trade field,${ }^{5}$ and in theoretical models they are still often formulated in the clever but unrealistic form of "iceberg costs," following Samuelson (1952). Fortunately, that simplification is not necessary for the correlation result, which permits all manner of resources to be used in accomplishing trade over all manner of routes. ${ }^{6}$

- Intermediate inputs: as noted above, it is the combination of trade costs with intermediate inputs that creates the most obvious problems for strong formulations of comparative advantage. Fortunately, the correlation result is proved for a formulation of technology that imposes no meaningful restriction on the use of goods as inputs to other goods. Thus all goods may be final goods, intermediate goods, or both. This aspect of the result seems to be increasingly important as "foreign outsourcing," or "offshoring," leads to increasing trade in intermediate inputs. 
- Arbitrary preferences: results in trade theory sometimes require rather strong assumptions about preferences, most commonly that they be homothetic. That is not the case for comparative advantage, which remains valid for all possible shapes of preferences. The result does require the Weak Axiom of Revealed Preference, which amounts essentially to assuming that countries behave as if they have well-defined community preferences. That is restrictive. But once you have those preferences, they may take any form.

- Goods may be services: although the items produced and traded in the formal model are called goods, they can just as well be services. In Deardorff (1985) I allow for services explicitly, taking account of various features that might differentiate services from goods, and I show there that the correlation result continues to hold.

- Goods may be dated: one can, in principle, treat goods produced in different years as different goods, and then view the model as describing equilibrium over time. This poses no problem for the correlation result, although it does perhaps limit its usefulness, since by saying nothing about trade in particular goods it now also says nothing about trade in particular years, such as the present.

- Goods may be differentiated: more generally, any amount of product differentiation can be allowed, simply by defining differentiated products as different goods (though subject to the strong restriction that markets for these differentiated goods still be perfectly competitive).

- Trade may be unbalanced: in Deardorff (1994) I dropped the assumption of balanced trade and found two ways that the correlation result would still hold. One was the aforementioned dating of goods, extending the correlation across time, the usefulness of which is that it allows a comparative-advantage explanation of why countries may run trade deficits and surpluses at different points in their life cycles. The other was to look at trade at a single time, at which it can still be shown to conform to comparative advantage even with a trade imbalance under the additional assumption that preferences are homothetic.

- Countries may be lumpy: failure of markets to be perfect within countries can certainly interfere with comparative advantage, as I will note below. However, one kind of imperfection does not seem to cause problems. If factors are immobile across geographical regions within a country—what in Courant and Deardorff (1992) we called "lumpy countries"- then I show in Deardorff (1994) that the comparative advantage correlations still go through.

This list of assumptions is rather long, intended to suggest that the law of comparative advantage really is quite robust. And importantly it should be understood that the proof of the correlation result starts, in all these cases, with showing the gains from trade, from which the pattern of trade then follows just as in the simpler models. However, there are plenty of assumptions that are not included in this list, and these suggest ways that, most importantly, countries may lose from trade and, less importantly, that the pattern of trade may not accord with comparative advantage. The most important of these seem to be the following:

\section{Assumptions Inconsistent with Comparative-Advantage Correlation}

- Domestic distortions: the perfectly competitive paradigm rests, of course, on the assumption that prices reflect true marginal costs and benefits. If there are external economies or diseconomies in production or consumption, or if market power causes prices to exceed marginal costs, then this will not be true. And if it is not, then economies will fail to maximize the value of their output, perhaps both with and 
without trade, and the arguments for comparative advantage do not go through. In Deardorff (1994) I briefly addressed this issue and showed that comparative advantage can be salvaged under a particular assumption about how distortions correlate with the changes in output that occur with trade. Unfortunately, this assumption is not particularly plausible. Therefore, for now at least, I think we must accept that domestic distortions interfere with the case for comparative advantage working its magic.

- Increasing returns: similarly, and often related to distortions, technologies may not be convex. If they are not, then this too interferes with the ability of a market economy to maximize value, especially globally, and as is well known this can lead countries to lose from trade. This is true even if the increasing returns are external to the firm, permitting markets to remain perfectly competitive. But in fact increasing returns are also likely to lead to market power of large firms and therefore cause domestic distortions along with non-convexity. In any case, my impression is that increasing returns are hard to reconcile with comparative advantage.

These assumptions undeniably cause problems for the theory of comparative advantage, both as a source of gains from trade and as a predictor of patterns of trade. And unfortunately there is also no denying that both domestic distortions and increasing returns are pervasive facts of economic life. What should be stressed, however, is that neither of these assumptions works systematically against comparative advantage, thus making its role less and less likely the more common they are. Rather, what these assumptions do is to complicate the story, not reverse it, and to complicate it to the point that we can no longer make confident predictions based on current knowledge.

A particular distortion such as a negative externality from production, for example, if it occurs in an export sector may reverse the gains from trade. But if the same distortion occurs in an import-competing sector, it will increase the gains from trade. And since a given sector must exist as both export and import competing in different countries, there may be no presumption that the existence of this distortion reduces the gains from trade worldwide. Likewise, the presence of increasing returns is known to increase gains from trade in some countries at the same time that it decreases or reverses them in others. Therefore, the very fact that distortions and increasing returns are ubiquitous may mean that their positive and negative effects on the gains from trade in different countries and industries will cancel out.

Or maybe not. Perhaps there is structure that we have not explored that will bias the net effects of all these complications in one direction or the other, either for or against trade. I don't know. My point here is just that the mere presence of frequent instances of distortion and increasing returns suggests only that we are ignorant, not necessarily that we are wrong.

\section{Conclusion}

Where does all this leave us? My own stake in this discussion probably would make it impossible for me to accept that comparative advantage is a useless concept. But I hope that the arguments reviewed here will convince others, too, that the concept of comparative advantage tells us something fundamentally important about the effects and determinants of international trade. A single concept can hardly be expected to explain every aspect of something as widespread and complicated as trade. But the theory gives good reason to believe that comparative advantage works, on average, to provide the potential for gain from trade and to explain what the nature of beneficial trade is likely to be. 


\section{References}

Anderson, James E. and Eric van Wincoop, "Trade Costs," Journal of Economic Literature 42 (2004):691-751.

Courant, Paul N. and Alan V. Deardorff, "International Trade with Lumpy Countries," Journal of Political Economy 100 (1992):198-210.

Deardorff, Alan V., "Weak Links in the Chain of Comparative Advantage," Journal of International Economics 9 (1979):197-209.

- "The General Validity of the Law of Comparative Advantage," Journal of Political Economy 88 (1980):941-57.

— "Comparative Advantage and International Trade and Investment in Services," in Robert M. Stern (ed.), Trade and Investment in Services: Canada/US Perspectives, Toronto: Ontario Economic Council (1985):39-71.

_ - "Exploring the Limits of Comparative Advantage," Weltwirtschaftliches Archiv 130 (1994):1-19.

, "Ricardian Comparative Advantage with Intermediate Inputs," North American Journal of Economics and Finance 16 (2005):11-34.

Dixit, Avinash K. and Victor Norman, Theory of International Trade, London: Cambridge University Press (1980).

Dornbusch, Rudiger, Stanley Fischer, and Paul A. Samuelson, "Comparative Advantage, Trade, and Payments in a Ricardian Model with a Continuum of Goods," American Economic Review 67 (1977):823-39.

Haberler, Gottfried, "The Theory of Comparative Cost and Its Use in the Defense of Free Trade" (1930); originally published in German in Weltwirtschaftliches Archiv 32 (1930):349-70; translated and reprinted in Anthony Y. C. Koo (ed.), Selected Essays of Gottfried Haberler, Cambridge, MA: MIT Press (1985):3-19.

Jones, Ronald W., "Comparative Advantage and the Theory of Tariffs: a Multi-Country, Multi-Commodity Model," Review of Economic Studies 28 (1961):161-75.

Samuelson, Paul A., "The Gains from International Trade," Canadian Journal of Economics and Political Science 5 (1939):195-205.

278-304.

\section{Notes}

1. In this case and the next, the figures show the case of a production subsidy, not an export subsidy. An export subsidy would cause a further drop in welfare as the consumption choice would also be distorted.

2. To get from an inner product of two vectors like (6) to a correlation, one works through the covariance, which is also the difference between the inner product and a product of the two vectors' means. The correlation therefore has the same sign as the inner product if one of the vector means is zero. In the four corollaries of Deardorff (1980), I formulate relationships that have this property by several devices, including normalization of prices, use of a condition of balanced trade, and in the most general result referred to here, use of the market-clearing condition that the sum of net trades across all countries must be zero.

3. Having said that, though, and having noted that export subsidies can undermine comparative advantage, the public might be justified in thinking that foreign export subsidies do justify trade intervention. In fact, while a foreign subsidy might cause us to trade contrary to our true underlying comparative advantage, it does not undermine our gain from doing so. It is only the subsidizing country that loses.

4. I am still indebted to Lars Svensson for drawing my attention to my failure to recognize this in an early version of Deardorff (1980).

5. See Anderson and van Wincoop (2004). 
1016 Alan V. Deardorff

6. The text of Deardorff (1980) uses an artificial assumption that all trade must pass through a single world "port," with respect to which transport technologies are defined. However, an appendix generalizes this to an arbitrary number of such ports, which can be located anywhere. 